\title{
THE ROAD TO LEARNING: USING GAMIFICATION AS AN EDUCATIONAL INNOVATION IN THE ERA OF DIGITAL EDUCATION
}

\author{
Oropeza I*, Muñoz R and Madero S \\ Tecnológico de Monterrey, Mexico
}

\begin{abstract}
As an educational innovation, Gamification is a process where the teachinglearning process integrates the principles of playfulness and games, motivating participation in a safe environment that permits mistakes without consequences. As a professional professors it was detected that the students assume, under the managerial concept, that as leaders, they are the ones who should give the orders, are responsible for the project, and in charge of others. With gamification, it is intended that they understand that as leaders, they form networks of teams with mutual interests (Draft and Lane, 2018). This raises the following question: Could gamification be the innovation that ensures students develop leadership skills and collaborative work? During the August-December semester of 2020, the game named $\mathcal{N}$ u da meya was designed and implemented where students taking two courses with little similarity helped each other in a fictitious customer-supplier working relationship where each student played a role to reach a common goal. The role play consists of one Fun Quest and five stages: Preparation, Brief, Script, Negotiation and the Master stage. Through the game ' $\tilde{\mathrm{Nu}}$ da meya, the students acquired knowledge through active learning. They developed the necessary leadership that allowed them to take the initiative in any field, challenge paradigms, and make things happen, ethically. This document shows how through gamification the students develop some competences and discover the value of leadership and collaborative work in realistic scenarios, where each of the participants played a role contributing to collaborative work, problem-solving, leadership, communication and decisionmaking in a shared environment of commitment. The importance of this project is understanding what makes teamwork efficient at the university level and for students' discovering the value of leadership and collaborative work and how to exercise them. This project demonstrates the tangible benefits of collaboration between different schools to perform multidisciplinary work.
\end{abstract}

Keywords: Digital Era, Innovative Practices, Gamification, Leadership, Teamwork, Interdisciplinary

\section{Introduction}

The Fourth Industrial Revolution currently being experienced has evolved rapidly in almost all areas, including educational, industrial, tourist, and personal (Schwab, 2016). According to the World Economic Forum (WEF), the transition of all educational systems to ones designed for the Fourth Industrial Revolution, that is, Education 4.0, requires learning mechanisms that more closely reflect the future of work and maximize the opportunities of the new technologies. These changes in learning experiences must be accompanied by proven innovative pedagogies, the teaching principles and strategies that underpin learning, innovation, flexibility and adaptation to change that have become primary drivers of growth (2020). 
Play environments have remarkable motivational power and attract students to participate often without receiving any reward, just the pleasure of playing within an engaging learning experience (Kapp, 2012). Thus, learning and feedback combined with play can transform the school into a much more exciting environment (Dicheva et al. 2015).

According Deterding, gamification employs some of the principles and mechanics of games such as points or incentives, narrative, immediate feedback, recognition, and freedom to make mistakes to enrich the learning experience (Deterding et al. 2015).

During the most disruptive upheaval ever experienced in education due to the COVID-19 pandemic, the 2020 UNESCO conference on digital technologies in education addressed the use of remote learning solutions. "Technology and internet access are essential elements to build more resilient, flexible and open systems," said Stefania Giannini during the opening ceremony. "Let's define together how to use technology to address this enormous challenge inclusively and equitably. We must now evaluate what did not work."

Education in the $4^{\text {th }}$ industrial revolution and the digital era

Klaus Schwab, Founder and Executive President of the World Economic Forum, points out that this fourth technological revolution will fundamentally alter how human beings live, work and interact. The processes of change and transformation will be different from anything that humanity has experienced before, calling for reinvention and flexibility, learning and unlearning in many ways (World Economic Forum [WEF], 2016).

The Organization for Economic Co-operation and Development (OECD) proclaims that education provides the key to shaping global megatrends, controlling the distribution of knowledge that is intrinsically linked to the distribution of educational opportunities. These days, digitalization connects people, cities, countries, and continents in ways that vastly increase individual and collective potential (Schleicher, 2019).

From the current economic perspective of constant change, the countries that can quickly generate and adopt new ideas, processes, and competitive products will have a competitive advantage over others. Along these lines, The Future of Jobs Report 2020 from the WEF shows that by 2025, machines will eliminate 85 million jobs, replaced by 97 million job positions that will be better suited to the changing division of labor between machines and humans. Current students must have the necessary skills to respond to these work challenges, such as problem-solving, critical and analytical thinking, self-management, active learning, resilience, stress tolerance and flexibility (2020).

García Ródenas (Gértrudix, Esteban, Gálvez and Rivas, (2017) states that academic institutions must be prepared to react to the demand for new professions and professionals; he posits that cognitive technologies will facilitate more personalized education in the future. Schleicher (2015) reiterates that students who do not develop competencies and skills in ICTs will endanger the economic, social and cultural life surrounding them. He describes the future in education where "the schools of tomorrow must help students think for themselves but also join empathetically with others at work and in their daily lives." 
According to the OECD, people at work, home, and the community will need a deep understanding of other cultures and traditions, regardless of the tasks that machines remove from humans in the workplace. The demand for new knowledge and skills will drive significant contributions to society's social and civic life. The soft skills that lead to innovation include curiosity, creativity, critical thinking, problem-solving and systems analysis, all of which will be in high demand in the labor market in the coming years (2011).

Likewise, The Future of Jobs Report 2018 from the WEF shows that structured and unstructured educational play activities encourage children to explore their natural curiosity, learn through trial and error, and develop solutions to new challenges (2018). This approach can be applied within formal and informal education. For example, in Finland, New Zealand, and Estonia, playful learning has been widely adopted and forms the foundation of early childhood education (Dickinson, 2019). Fostering innovation and creativity will require a shift toward more interactive instructional methods in which teachers act as facilitators and coaches rather than lecturers. It will also require collaboration between educational systems and the private sector to understand how developing skills in these areas can support innovations in the real-world (WEF, 2018).

As technology continues to automate routine tasks, human-centered skills will provide a distinct advantage over machines in the workplace. In fact, employers report that leadership, social influence, and emotional intelligence are among the future's high-demand interpersonal skills (WEF, 2018).

Marchesi and Marti (2003) report that the teaching model mostly shared by teachers and students using ICTs in the classroom is expository and transmits information. It does not necessarily imply an innovation or a significant alteration of the teaching model that the teacher usually uses. They also point out that in this model, the computer is an instrument that helps the student expand information, perform exercises, or facilitates interactive relationships. However, it is used with the same objective: that the student learns specific content and accounts for that knowledge in the corresponding assessment (Area, 2008).

Sawyer (2015) emphasizes the power of technology to influence and improve academic processes by providing experiences that lead to deeper learning. These experiences allow students to learn collaboratively, test and redesign models and articulate their knowledge visually and verbally. Interdisciplinary insights from the learning sciences are leading to new approaches to education. While experts believe that the human psychology underlying learning has not changed much over time, the external factors that affect how we understand, retain, and receive new material continually evolve. As the digital revolution accelerates, technology provides us with exciting opportunities to shape learning experiences to achieve learning goals (Frezzo, 2017).

Prensky (2001) famous for coining the term digital natives, raises the need to invent digital native methodologies for all subjects, at all levels, using the students as guides. For María Carmen Buelga, a specialist in social psychology at OECD, technology in education implies a new paradigm in which children and young people cease to be passive recipients and repeaters of the information transmitted to them and become the protagonists of the activities (Garduño, 2019).

Schleicher (2016) states that "it is wrong to think that excellence in teaching will cease to matter in this digital age, and we can come to think that teachers can be easily replaced by platforms or digital 
content that can adapt to the needs of each student. The role of the teacher in the development of new, more pertinent and effective educational practices is key since they will be the promoters of this new educational paradigm with the implementation of renewed educational practices". For Schleicher (2016), more important than including technology is the pedagogy; it should focus on the students as the active participants in their search for knowledge, equipping them with inquiry tools and collaborative learning spaces that facilitate practical and cooperative activities. The United Nations Educational, Scientific, and Cultural Organization, UNESCO (2016), says that technology will be the tool to make essential changes in the way students are evaluated by facilitating real-time training assessments. Technology will also support learning communities and teaching with virtual laboratories, sophisticated experiment and simulation software, social media, and game-based learning.

One must consider the following aspects to develop an educational teaching-learning practice model supported by ICT (Area, 2008):

1. Train the students to reconstruct and give meaning to all the information they obtain from various media and develop the skills to examine data intelligently, critically, and ethically.

2. Develop a teaching methodology that does not rely on the textbook to be the sole source of knowledge. Instead, stimulate the students to search for new information using various sources and technologies. Teach the students always to reflect and contrast data critically.

3. Raise problems and challenges of interest and significance for the students to articulate the work plans and develop the necessary actions. Provide them with the technologies to develop satisfactory problem solutions. Require them to present their solutions to learn to express themselves and communicate using different media and technological resources.

4. Organize tasks and activities that involve using technology that supports collaborative learning processes among the students in the classroom and geographically distant classes (e.g., remote learning).

5. Assume that the teacher's role in the classroom should be more of an organizer, guide, facilitator, and supervisor of technological learning activities than a transmitter of elaborated information.

\section{Educational innovation}

The result of all the changes and digitalization of the Fourth Industrial Revolution is that educational institutions must develop different teaching methods. These new ways of transmitting knowledge are part of educational innovation, which means implementing a transformation in the teaching-learning process that incorporates changes in the materials, methods, contents, or contexts involved in teaching (López and Heredia, 2017).

Although educational innovation is not an absolute concept, its value as an agent of digital transformation in higher education is indisputable. Educational innovation is student-centered and supported by the necessary technological tools that are authentic stimuli for change, leading to the development of teaching and learning processes with a wide variety of techniques to acquire relevant 
knowledge. The new techniques are disruptive and transformative, changing teachers' and students' relationship and performance, building new models to create work and learning and teaching environments. (Gértrudix et al. 2017)

For Barrio, Rivas, Esteban and Gálvez (2017), the main objective is to promote renewal and continuous quality improvement in what will be taught, paying better attention to the current needs and demands of remote teaching. It means developing new teaching methods, reflecting broadly on the value of educational innovation as an agent of digital transformation and diversity in higher education; this process requires continuous, permanent, and evolutionary work.

On the other hand, Zabalza (2011) suggests that the essential components of desired teaching methodologies consist of organizing space and time, supplying information in relevant ways through the proper orientation and management of learning activities and interpersonal relationships. Pardo (2014) refers to online teaching as a new teaching modality that requires new methodologies and ways of organizing teaching, the course, the teacher's work and the students' assignments.

It is also necessary to mention that the physical environment does not necessarily have to be in a classroom nor even in an educational institution. Innovation allows the learning-teaching process to be synchronous and asynchronous, and the course design uses challenges and activities in the learning process. Current technology enables e-Learning or Online Learning, which can be customized to the institutions or teachers' academic and technological needs (Ibáñez, 2020 ). These modalities include:

\section{Online education}

Teachers and students participate and interact in a digital environment synchronously, supported by technological resources, facilities, and internet and computer networks; their schedules for the session must coincide. The classes can be conducted in Zoom or Teams sessions, supported by platforms such as Zoom, Canvas, and Blackboard.

\section{Virtual education}

This modality requires technological resources, such as a computer or tablet, an internet connection, and the use of a multimedia platform. Unlike online education, these classes are asynchronous; i.e., teachers' and students' attendance do not have to coincide in time. Course materials or documents are uploaded to the chosen platform so that students can review them, and questions are usually discussed in public forums by the whole class. It is supported by platforms such as Canvas, Blackboard, Edmodo, Schoology or email.

\section{Remote education}

This modality offers a hybrid of presential and virtual classes. Students have control over the time, space, and pace of their learning because it does not require an internet connection or computational resources, as in other methods. The materials used are ordinarily physical, such as notebooks, pens, colors, and USB sticks. The technological part is carried out through email or chat/messenger services, such as WhatsApp. It can also be done through television, radio, and other physical resources such as textbooks, books, etc. 


\section{Emergency remote education}

Emergency remote education was born as a result of the COVID-19 global crisis in March 2020. Education confronted an extreme challenge since it had to adapt its methods in a brief time to continue the education of all its students. The main objective was to transfer the courses that had been taught in-person to a remote, virtual, distance or online classroom. Each institution adapted its model according to its possibilities.

In these four modalities, the teacher's role is critical. They devise, create, develop, and implement required innovations. The teacher serves as tutor, guide, or mentor to autonomous, flexible, selftaught, enterprising, creative, socially skilled young people who are capable of leading teams, tackling global projects, and collaborating with professionals worldwide who speak other languages and come from other cultures (Gértrudix, Esteban, Gálvez and Rivas, 2017).

\section{Gamification}

According to John Godwin, CEO of the Lego Foundation, gamification is a process of educational innovation that it is developed in a real or virtual educational environment emphasizes that learning through play has a fundamental role in education. Educational systems worldwide will need to evolve to better meet a rapidly evolving economy and society. While the traditional literacy and numeracy metrics of education are vital, society also requires students to have various creative, technological, innovative, and interpersonal skills to thrive in the modern world in more accessible, personalized, and active ways than ever before (Goodwin, 2020).

To better understand Gamification, it is worth distinguishing between the similar terms of ludification and game-based learning. Zepeda (2019) defines ludification as a set of strategies that includes gamification, playful design, and game-based learning. Game-based learning consists of teaching through an existing game or creating a game with an educational purpose; however, the entire learning experience occurs while playing. In Gamification, students' participation in class, how they engage in classroom activities, and the activities and tasks are relevant aspects of the game. In other words, there is no game; instead, it is to make students think there is a game" (Román, 2019).

Gamified learning occurs when the activity is experienced as fun, helps students find meaning in what they are doing or learning, actively engages their minds through iterative thinking (e.g., experimentation, hypothesis testing), and presents opportunities for social interactions. If game elements are integrated into learning supported by technology, they provide students with contextually acquired knowledge that develops various holistic, cognitive, creative, physical, social and emotional skills (Goodwin, 2020).

\section{Objective}

The research goals introduce gamification in the classroom to develop competencies in leadership problem-solving, collaboration, and communication, and meet the needs of current generations and train professionals seeking that their experience and their profession are at the service of the team, community, family and society.

This investigation seeks to answer the following questions: 
- How can students develop leadership skills allowing them to take the initiative in any field including a digital environment, challenge paradigms, and make things happen, ethically?

- Is gamification an educational innovation the answer to helping the students develop necessary competencies to assume leadership roles in teams working collaboratively, both in-person and remotely?

Gamification as an educational alternative creates dynamic, fun, and challenging environments that allow students to develop competences and attitudes to solve challenges they confront, becoming leaders of teams, and interacting with others in a social and professional environment.

We seek to prove that through technology, innovation and gamification, students can enjoy the process with motivation and engagement, acquiring the necessary skills to develop creative solution strategies for the challenges they face and become ethical servant leaders.

Using digital plataforms like Zoom as a tool for students to allow their video communication including weekly meetings teams, remote work and negotations.

\section{Diagnosis preview test}

At the beginning of the Semester a 7-question survey was applied to 149 students as part of the research. Among these, the next question was included: According to your experience, evaluate the concepts mentioned when the students worked in collaborative teams from 1 to 5 , where 1 indicated high importance, 2 meant medium-high importance, 3 was neutral, 4 signified medium-low importance, and 5, low importance. 


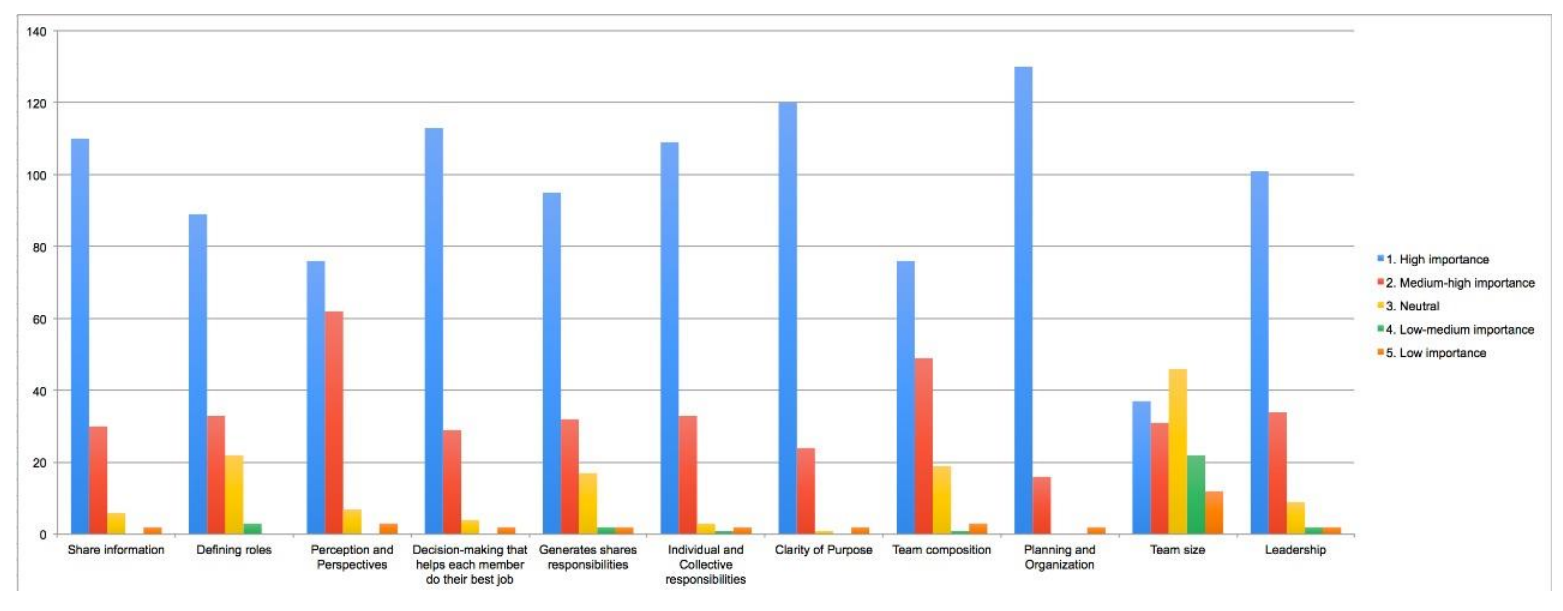

Figure 1 Question survey

In this survey (Figure 1) it can be concluded that Planning and organization, Clarity of purpose, Decision-making that helps each member do their best job, Individual and collective responsibilities, and Leadership were the most relevant for students to carry out their work in collaborative teams.

Team size was not relevant or highly important to most students when they are faced with working on teams.

\section{Methodology adopted}

During six weeks between October and November 2020, a game was played with the following characteristics:

The game is designed for the relationship dynamics between the client (Hospital), the Legal Office, and the supplier (Production house). The game triggers the social and professional relationships that occur in a business environment between clients and suppliers. It exposes students to various leadership types, emotional intelligence, tolerance of frustration, resilience, etc.

Game metaphor: competency based on a challenge.

Objective: To solve the image problem that a fictional hospital has with its target market.

Scenario: The client is a hospital with an image problem. The supplier consultant is a production company that will help solve the problem.

Game: 'Ñu da meya, a Mexican indigenous Otomí dialect name that means "Road to Learning."

Role play Participants: There will be a list of Positions (assumed by characters) within each of the companies in the game: Hospital, Production House, and Legal Office. The team members will choose their characters and determine their physical characteristics, responsibilities, and attitudes, which must correctly correspond to the profile for their position.

Team 1- Subject: Organizational Behavior and Development of Human Talent. Hospital Team 2 - Subject: Organizational Behavior and Development of Human Talent. Legal Office 
Team 3 - Subject: Multiplatform TV Production. Supplier Consultant

Game background: This game occurs in the following scenario:

A fictional Hospital, for many years, has played a significant role in its city's history. The founding partners had decided to close this central hospital because it was no longer profitable, and its reputation had declined. The reasons that had led the partners to make this decision were due to high staff turnover, a bad reputation, negligence, and the occurrence of organ trafficking. The final decision of the partners was not to shut down, but they asked the hospital managers to clean up the hospital's image through an audiovisual production. The hospital administrators must hire an audiovisual "Production House" to carry out this work. The production company will be the hospital's supplier, developing a product: audiovisual material in television format (newscast or magazine type) in which the hospital's image problem will be improved.

During the game, the Hospital will have the support of a Legal Office that will act as a legal/accounting advisor and will be responsible for keeping the meeting minutes between the client, "Hospital / Legal Office" and the Supplier, "Production Company".

The game consists of 5 stages:

The game has an ice-breaker session: Fun Quest for the members of the Hospital, Legal Office, and Production House before starting the formal game. The intention is to get to know each other as people and students and find common interests, facilitating good negotiations in the subsequent stages.

Preparation stage: Students choose the role they want to play and personify, defining their physical and attitudinal characteristics. According to the chosen role, the students write the description of their position and place their photograph, objective, and the responsibilities that they must assume throughout the game.

Briefing Stage: At this stage, business cards are presented and exchanged. The client Hospital and Legal Office comment on their needs, presenting their "brief" to the Production Company, who, in turn, presents the profile of their company.

Script Stage: In this third stage, the supplier Production Company presents the script to the client Hospital and Legal Office. The negotiation will be carried out until a satisfactory agreement is reached by the parties involved, and then they continue to the next stage.

Negotiation Stage: In this fourth stage, the supplier Production Company presents the proposed budget to the client Hospital and Legal Office. The pertinent negotiations will be carried out until a satisfactory agreement is reached by the parties involved. The team that achieves the best negotiation will obtain the "Master Negotiator" Badge of Recognition

Master Stage: Production of the video and presentation to the client and target market. 


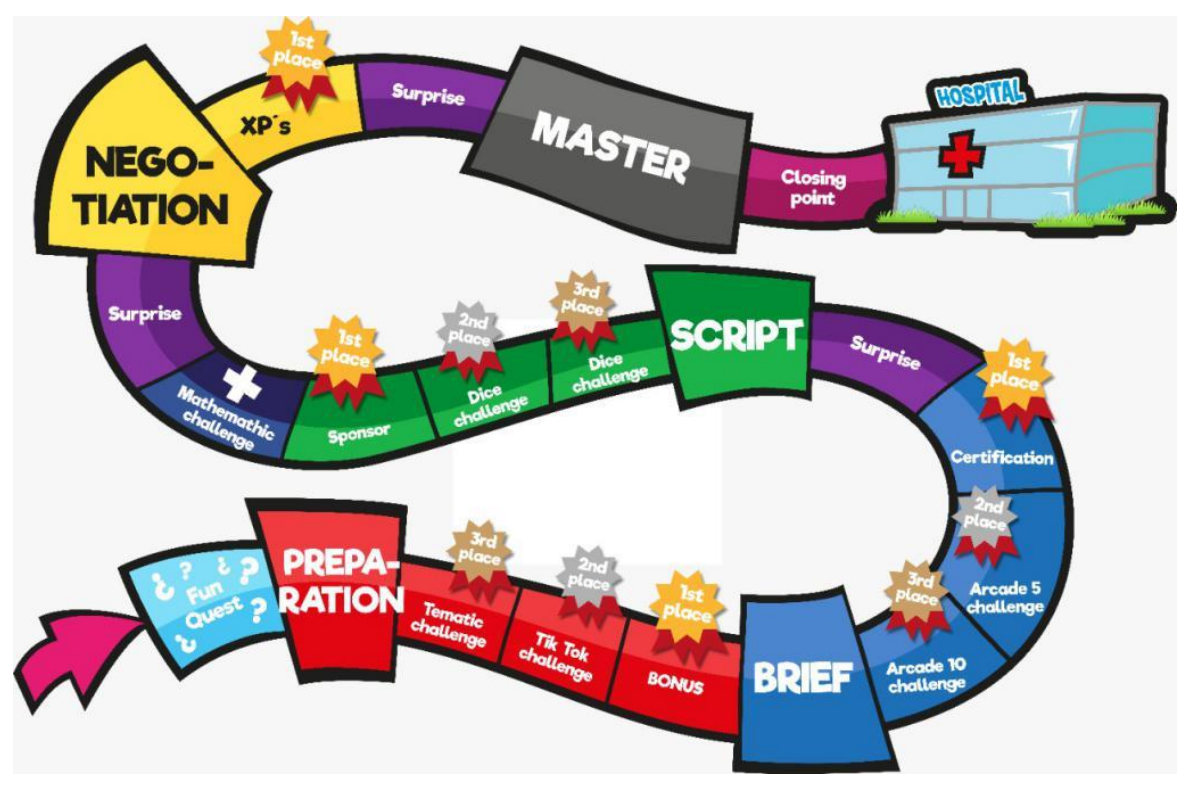

Figure 2 Game board with 5 stages.

In each of the stages, the first team to present the requested evidence will occupy the first place box, obtaining a prize. The second and third-place teams will confront a challenge that they must resolve satisfactorily to continue to the second stage.

As there is a client-supplier relationship, the client Hospital has a defined budget, which is provided by the teacher. The funds from this budget pay for the services provided by the Production Company.

The Production Company has operating and administrative expenses provided by the teacher. These are the operating expenses that the company incurs for the preparation of the video requested by the Hospital.

Each of the challenges is designed for students to develop effective communication, teamwork, and conflict management skills. The challenges presented at each stage are different.

As in real life, time is also a challenge to consider during the game because the game always rewards the team that first complies with the requested "deliverable."

A board (Figure 3) will be used to see their progress, that is, what they have accomplished, what they are doing, and what they will be doing. The students will see the five game stages and their intermediate steps. Badges earned during the game will also be displayed on the scoreboard for each team. 


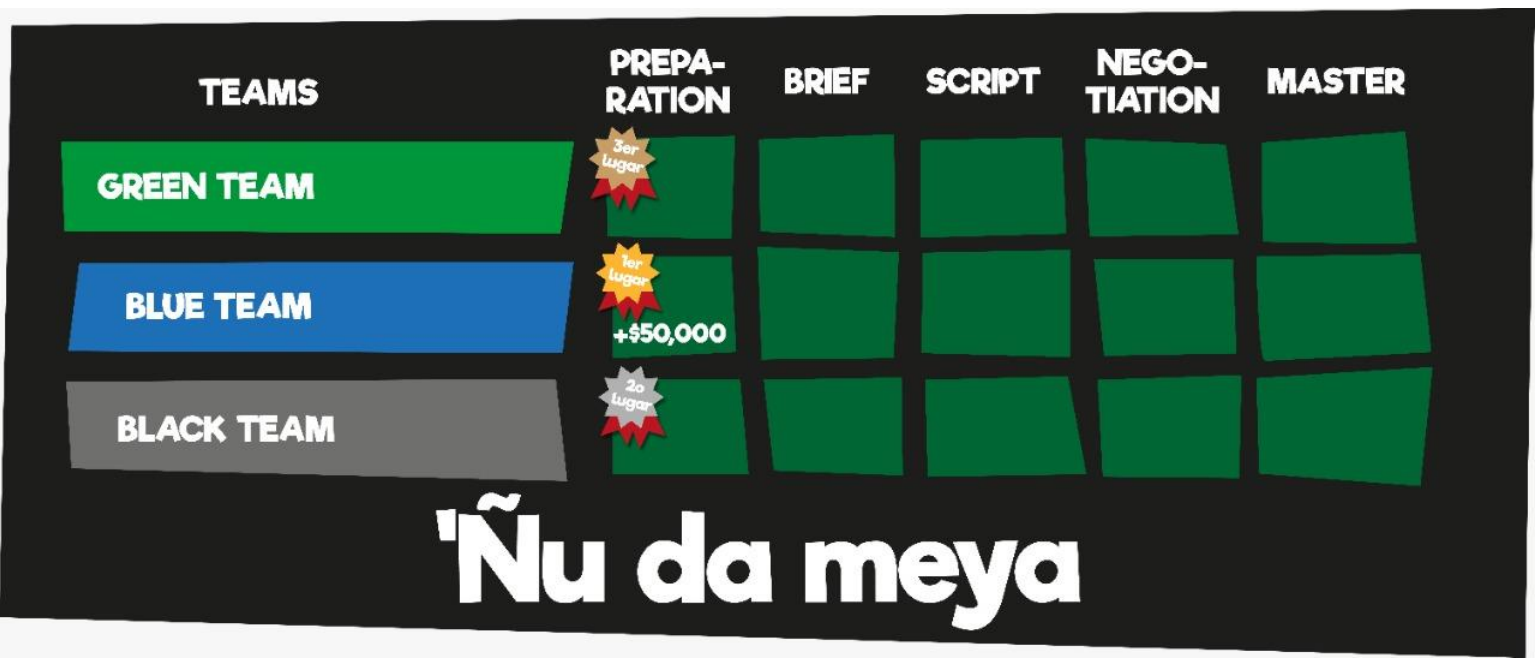

Figure 3. Game board

The game design aims to provoke emotions and motivations through bonuses, rewards, punishments, tests, etc. Depending on the stage and the test, games are activated to decide what type of reward or punishment they will receive. For example, there will be an economic bonus to the team that completes the activity first in the Preparation and Brief stages. The losers receive a penalty, which can be financial or an additional activity requirement (Figure 4).

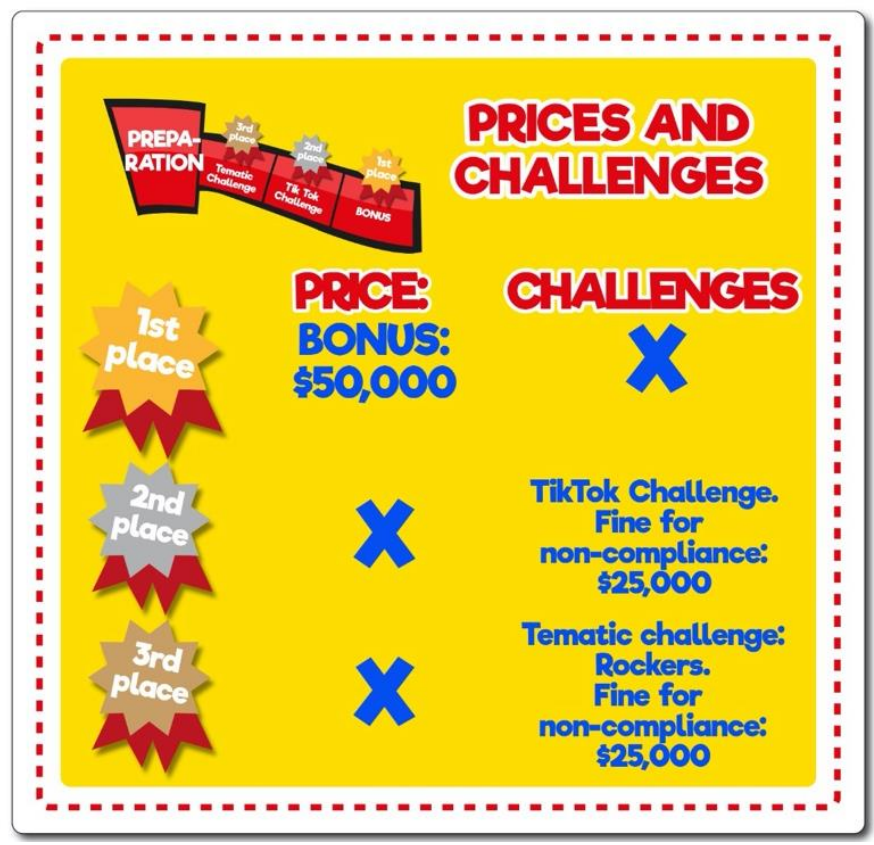

Figure 4. Prices and Challenges card.

\section{Conclusions}

Through the game 'Ñu da meya, the students learn to participate in their acquisition of knowledge through active learning and become servant leaders through playing roles in scenarios, in essence, rebuilding themselves. They develop the necessary leadership, active communication skills and work collaboratively that allows them to take the initiative in any field, challenge paradigms, and make things happen, ethically. 
The teachers implement an educational innovation in the classroom in two subjects with overlapping topics in different schools, seeking to make the activity replicable, as long as the scenario sets up a client-provider relationship in a fictitious environment (with real-life situations).

Any class that departs from the traditional method of teaching will be new and attractive for the students, offering them alternative, multidisciplinary, and technological spaces.

At the end of the school semester, a 16-question Exit Survey was applied to the game's student participants as part of the research and the game. Among these, the question was included: Did you like the game? Of the 37 students who answered the question, 27 answered Yes. In questioning the reasons why they liked it, the students mainly emphasized that the game allowed them to role play a company representative in a fun way, have a real-life experience with situations and problems that they probably will face in their professional future, meet and interact with students in other disciplines, and acquire leadership and collaborative competencies.

Also, the Exit Survey asked them to assess their satisfaction in the game. The possible answers were totally satisfied, very satisfied, moderately satisfied, little satisfied, and unsatisfied. Of the 38 students who answered the question, 17 said they were totally satisfied, 14 very satisfied and 7 moderately satisfied. None answered little satisfied or unsatisfied.

The students' high satisfaction in the game correlates to positive results and the satisfaction of performing the task well under the circumstances faced. According to Barragán, Wellington and Giovanny (2015). emotion and satisfaction are conditional factors for more effort and best performance and the feeling of individual and collaborative success, which builds character and drive in the personality and leads to joy at work.

The project demonstrates novel and relevant challenges in teacher-controlled environments where students rebuild themselves as leaders through their curiosity, collaboration, passion, imagination and fun time.

\section{Acknowledgements}

This study has been supported by Writing Lab.

\section{References}

Area Moreira, M. (2008). La innovación pedagógica con TIC y el desarrollo de las competencias $\begin{array}{lllll}\text { informacionales } & \text { y } & \text { digitales. } & \text { 15-17. } & \text { Retrieved }\end{array}$ https://revistas.awpruebas.es/index.php/IE/article/view/7157

Barragán, L., Wellington, E., Calle, C. and Giovanny, O. (2015). Tesis. Retrieve from: http://repositorio.ug.edu.ec/handle/redug/21528

Cameron, E. and Green, M. (2017). Essential leadership: develop your leadership qualities through theory and practice. London: KoganPage.

Contreras, F., Barbosa D., and Piñeros R. (2016). Liderazgo: antecedentes, tendencias y perspectivas de desarrollo, implicaciones para la organización actual. Colombia, Universidad del Rosario. 
Deterding S., Dixon D., Khaled R. and Nacke L. (2015). From game design elements to gamefulness: Defining "gamification". 15 ${ }^{\text {th }}$ International Academic MindTrek Conference: Envisioning Future Media Environments.

Dicheva D., Dichev C., Agre G. and Angelova G. (2015). Gamification in Education: A Systematic Mapping Study. Educational Technology \& Society.

Dickinson, K. (2019, February). "How does Finland's top-ranking education system work?" Retrieved from https://www.weforum.org/agenda/2019/02/howdoes-finland-s-top-ranking-education-system$\underline{\text { work }}$

Draft R. adn Lane P. (2018). The leadership experience. Australia, Cengage Learning.

Frezzo, D. (2017, May). The role of technology in the education of the future. Retrieved from https://www.weforum.org/agenda/2017/05/science-of-learning

Garduño, V. (2019, April). ¿Porqué es importante la Educación Digital? Retrieved from https://historico.mejoredu.gob.mx/por-que-es-importante-la-educacion-digital/

Gértrudix, M., Esteban, N., Gálvez, M. and Rivas, B. (2017). La innovación educativa como agente de transformación digital en la Educación Superior: acciones para el cambio. Madrid, Spain: Dykinson.

Goodwin, J. (2020). Learning through play: how schools can educate students through technology. 2021, from World Economic Forum website: https://www.weforum.org/agenda/2020/01/technologyeducation-edtech-play-learning/

Hertz H. (2013). Games can make "real life" more rewarding, Edutopia. Retrieved from http://www.edutopia.org/blog/games-make-real-life-rewarding-m

Ibáñez, F. (2020). Educación en línea, Virtual, a Distancia y Remota de Emergencia, ¿cuáles son sus características y diferencias? Retrieved from https://observatorio.tec.mx/edu-news/diferenciaseducacion-online-virtual-a-distancia-remota

Kapp K. (2012). The Gamification of Learning and Instruction. Game-based methods and Strategies for Training and Education. San Francisco, Pfieffer.

Lee J. \& Hammer J. (2011). Gamification in education: What, how, why bother? Academic Exchange Quarterly.

López, C. and Heredia, Y. (2017). ¿Qué es innovación educativa? Observatorio de Innovación Educativa del Tecnológico de Monterrey. Retrieved from https://observatorio.tec.mx/innovacioneducativa\#: :text=Una\%20innovaci\%C3\%B3n\%20educativa\% $20 \mathrm{implica} \% 20 \mathrm{la}$,contextos\%20implicados\%20en $\% 20 \mathrm{la} \% 20 \mathrm{ense} \% \mathrm{C} 3 \% \mathrm{~B} 1$ anza.\&text=\%C2\%BFQu\% C3\%A9\%20es\%20innovaci\%C3\%B3n\%20educativa\%3F,-Glosario\%20de\%20innovaci\%C3\%B3n

Pardo, V. (2014). La docencia online: ventajas, inconvenientes y forma de organizarla. Roderic, 18, 622-635. Retrieved from https://roderic.uv.es/handle/10550/41511

Prensky, M. (2001, October). Digital Natives, Digital Immigrants. Retrieved from https://www.marcprensky.com/writing/Prensky\%20-

\%20Digital\%20Natives, \%20Digital\%20Immigrants\%20-\%20Part1.pdf

Román, R. (2019). Gamificación: mitos y realidades. Retrieved from https://observatorio.tec.mx/edunews/gamificacion-mitos-y-realidades

Schleicher, A. (2019, January). What the fourth industrial revolution could mean for education and jobs. Retrieved from https://oecdedutoday.com/what-the-fourth-industrial-revolution-could-mean-foreducation-and-jobs/

Schools of the Future: Defining New Models of Education for the Fourth Industrial Revolution. (2020, January). Retrieved from: http://www3.weforum.org/docs/WEF_Schools_of_the_Future_Report_2019.pdf 
Skills for Innovation and Research, (2011). Retrieved from https://doi.org/10.1787/9789264097490$\underline{\text { en }}$

Tecnologías digitales al servicio de la calidad educativa: una propuesta de cambio centrada en el aprendizaje para todos. (2016). Retrieved from https://unesdoc.unesco.org/ark:/48223/pf0000245115

The Future of Jobs Report 2018. Retrieved from http://www3.weforum.org/docs/WEF_Future_of_Jobs_2018.pdf

The Future of Jobs Report 2020. (2020, October). Retrieved from https://www.weforum.org/reports/the-future-of-jobs-report-2020/in-full/executive-summary

World Economic Forum (14 Jan 2016). The Fourth Industrial Revolution: what it means, how to respond. 202. Retrieved from: https://www.weforum.org/agenda/2016/01/the-fourth-industrialrevolution-what-it-means-and-how-to-respond/ 